\title{
USING OF HIGH PHOSPHORUS GRAY IRON FOR THE STUB- ANODE CONNECTION IN THE ALUMINIUM REDUCTION CELLS
}

\author{
Mohamed M. Ali ${ }^{1}$, Adel Nofal ${ }^{2}$, Amr Kandil $^{3}$, and \\ Mahmoud Agour ${ }^{4}$ \\ ${ }^{I}$ Al Azhar University, Faculty of Engineering, Qena, Egypt \\ ${ }^{2}$ Central Metallurgical R\&D Institute (CMRDI), P.O. Box 87 Helwan, \\ Egypt \\ ${ }^{3}$ Al Azhar University, Faculty of Engineering, Cairo, Egypt \\ ${ }^{4}$ Aluminum Co. of Egypt (Egyptalum), Nagaa Hammadi, Egypt
}

(Received April 19, 2011 Accepted October 8, 2011)

High phosphorus gray iron (HPGI) is used to secure the steel stub of an anode rod to a prebaked anode carbon block in the aluminium reduction cells. During this work, a detailed characterization for HPGI was done. The variation in the chemical composition of the HPGI collar, anodic voltage drop, and collar temperature over the 30 days anode life cycle were studied and compared with HPGI microstructure at different stages of the experiment. The carbon content in HPGI during anode life cycle was reduced from 3.73 to $3.38 \%$. Significant changes in the HPGI microstructure were observed after 3 and 30 days from the anode changing. The collar temperature increases over the anode life cycle and reaches to $850^{\circ} \mathrm{C}$ in four weeks after anode changing. Different changes in the anodic voltage drop values at the stub-collar-anode connection during anode life cycle were recorded.

Two bench- scale experimental set-ups were designed and implemented to simulate the operating conditions in the steel stub/ HPGI collar/ anode block connection and used to measure the electrical resistance and resistivity respectively. Comparison with steel electrical resistivity showed the greatest importance to modify the current HPGI or producing new alloys with excellent electrical and mechanical properties. The steel stub and HPGI thermal expansion were measured and studied. Considerable permanent expansion was observed for the HPGI collar after the completion of the heating-cooling cycle.

\section{INTRODUCTION}

Cast iron plays an important role in the extraction of aluminium from alumina by HallHeroult process. At Egyptalum, a prebaked anode carbon block with four stub holes is attached to an anode hanger by pouring molten HPGI in the gap between the stub and the anode block $[1,2]$. The composition of cast iron has been designed to ensure high fluidity in order to fill the gap between these two components. Cast iron is probably the material of choice more for it's excellent founding characteristics than it's electrical conductivity [1]. The effect of the main constituents $(\mathrm{C}, \mathrm{Si}, \mathrm{S}, \mathrm{Mn}$ and $\mathrm{P})$ on cast iron 
properties is described [3- 5]. Phosphorus has been believed to enhance contact between cast iron collars and anode carbon leading to lower stub-anode voltage drop $[1,6]$. Meanwhile increased phosphorus contents may enter the molten electrolyte by attack of cast iron collars resulting in phosphorus contamination of primary aluminum and lower current efficiency. Moreover, phosphorous has been shown to increase the electrical resistivity and reduces the thermal conductivity of cast iron significantly [7]. The electrical resistivity of gray iron also increased with increase in $\mathrm{C}$ and $\mathrm{Si}$. Manganese and sulfur react to form MnS, forming inclusions that further affect the electrical characteristics of the rodding process.

Peterson [8] instrumented an anode with 30 voltage probes and 50 thermocouples. Temperature and potential reading were taken during 24 hours while the anode was in operation up to $25 \%$ of the anode voltage was attributed to steel-cast iron-carbon connection. He concluded that the contact resistance at the cast iron to carbon transition increases the anodic voltage drop. Brooks and Bullough [9] investigated the contact voltage drop in an anode-stub assembly with variation of the cast iron thickness. The authors determined that the decrease in contact resistance brought about by carbon strain was maximized up to about $550^{\circ} \mathrm{C}$. Barstow, et al. [1] published the efficient cast iron microstructure for anode-collars in gray irons. Wilkening and Cote [10] published the results of measurements of electrical resistivity, thermal conductivity and thermal expansion as a function of temperature for the three constitutive materials. They concluded that the average voltage drop over approximately $90 \%$ of the anode cycle time is about $12 \mathrm{mV}$ between stub and cast iron and about $120 \mathrm{mV}$ between stub and carbon anode.

In this work, the performance of the existing HPGI connection collar in the course of service cycle of an operational cell was studied by measuring the voltage drop between the steel stub and the anode carbon block and the collar temperature measurement. The variation in voltage drop was correlated to the changes in HPGI microstructure over a complete life cycle of the anode i.e. up to 30 days and at increasing temperatures up to $850^{\circ} \mathrm{C}$. The electrical resistivity, resistance and thermal expansion for HPGI samples were tested and evaluated.

\section{ANODE VOLTAGE DROP}

The applied cell voltage is normally between 4.0 and $5.0 \mathrm{~V}$ in the aluminium reduction cells $[7,11$, and 12]. This relatively large variation is not only due to the different types of cells and methods of operation, but also to the choice of boundaries of the cell for the voltage balance. Controlling in the anode voltage drop is considering a major factor to achieve good efficiencies. This is often seen as totally a pot room function, yet significant contributions can be made in the rodding plant. For a typical total reduction cell voltage of $4.60 \mathrm{~V}$ it is generally accepted that $0.30 \mathrm{~V}$ is attributable to anodic voltage drop which is defined as the ohmic voltage drop measured from the anode bus bar to the bottom of the anode block.Table1 shows details typical contributions to the total anode drop and that $6.5 \%$ of the total energy used in the reduction process is lost to ohmic voltage drop. Further, the stub-carbon drop is no less than $40 \%(0.12 \mathrm{~V})$ of the total anode drop and is attributable to processes [13]. This literature shows the stub-anode voltage drop is of the same order of magnitude as the average voltage drop in the anode itself during its service cycle [11]. The potential of 
reducing the voltage drop between stub and anode is greater than in the anode itself. Such voltage drop across the stub-anode interface is usually taken as a measure for the cast iron collar performance.

Table 1- Anode voltage losses [13]

\begin{tabular}{|l|c||l||}
\hline \multicolumn{1}{|c|}{ Item } & \multicolumn{1}{|c||}{ Value, V } & \multicolumn{1}{c||}{ Remarks } \\
\hline \hline Clamp drop & 0.02 & $\begin{array}{l}\text { Contact surface conditions and clamp } \\
\text { tightness are variables }\end{array}$ \\
\hline \hline Rod drop & $\begin{array}{l}\text { 0.08 divided to } \\
\text { Aluminium rod }=0.05 \\
\text { Transition joint }=0.01 \\
\text { Steel yoke }=0.02\end{array}$ & $\begin{array}{l}\text { Rod drop is relatively constant. } \\
\text { Transition joint weld variable. }\end{array}$ \\
\hline \hline Stub-carbon drop & 0.12 & $\begin{array}{l}\text { Depends on stub repair quality, cast } \\
\text { iron quality, stub alignment in anode } \\
\text { holes and stub graphite coating. }\end{array}$ \\
\hline \hline Carbon drop & 0.12 & $\begin{array}{l}\text { Anode block drop is proportional to } \\
\text { the height of the anode block. }\end{array}$ \\
\hline \hline Total & 0.34 & - \\
\hline
\end{tabular}

\section{EXPERIMENTAL WORKS}

\section{1- The chemical composition of the HPGI}

Egyptalum has a big rodding plant started production in 1997. The main purposes of rodding process are to make a strong mechanical connection, and make a good electrical connection between steel stub and anode carbon block. HPGI is poured in the stub holes to fill the gap between the steel stub and anode block, and the anode ring formed is usually referred to as collars or thimbles. The quantity of HPGI used for each anode block equals $25 \mathrm{~kg}$. The elemental analysis of the HPGI is done by ARL 3460 simultaneous quantometer.

\section{2- Measurements of collar temperature, anodic voltage drop at} the stub-collar - anode connection and anode current during the

\section{anode life cycle}

The collar temperature, anodic voltage drop variation at the stub-collar - anode connection and anode current dependence on the anode life cycle under normal cell operating conditions were measured. To correlate the temperature increase of the HPGI collars with the variation in their microstructure, anode current and anodic voltage drop at the stub-collar-anode connection, thermocouples were inserted in the collars and their temperatures were measured every one hour during the first day and then, once a day over 30 days (anode life cycle). Meanwhile, for voltage drop measurements copper electrodes were inserted in the anode carbon block at $50 \mathrm{~mm}$ from the HPGI collar and in steel stub at $100 \mathrm{~mm}$ above the collar surface. 


\section{3- Microstructure of HPGI Collars under normal cell operating}

\section{conditions}

Samples from the as cast HPGI collars were machined and polished for microstructure investigation. The change of the microstructure of the HPGI Collars was studied after 3 days and after 30 days (at the end of the anode life cycle). The model of optical microscope used in this work is Gold MCX1700.

\section{4- Electrical resistivity and resistance measurements}

The investigated HPGI were melted in $100 \mathrm{~kg}$ medium frequency induction furnace. To simulate the operating conditions in the steel stub/ HPGI collar/carbon anode block connection, the bench-scale experimental set-up shown in Figure 1 was designed and used for the electrical resistance measurement. Carbon blocks 150 x 150 x $150 \mathrm{~mm}$ were cutted from the same anode carbon material and a stub hole $70 \mathrm{~mm}$ diameter was machined in the centre of the carbon block. Steel bars $60 \mathrm{~mm}$ diameter and $120 \mathrm{~mm}$ long were machined from Steel37 used to hang anodes in the actual electrolytic cells and fixed in the centre of the stub hole. The investigated HPGI melts were poured in the gaps between the cylindrical steel bars and carbon blocks. Six blocks were worked. Five blocks from them were placed in a resistance muffle furnace and gradually heated. Blocks were withdrawn from the furnace when the temperature reached 500, $600,700,800$ and $850^{\circ} \mathrm{C}$ respectively. Individual blocks were held for two hours at each temperature before being taken out of the furnace for cooling. Y-blocks from each of the investigated HPGI were used to machine cylindrical rods $15 \mathrm{~mm}$ diameter $\mathrm{x} 200$ $\mathrm{mm}$ length, which were used to measure the resistivity of the HPGI using the set-up illustrated in Figure 2.

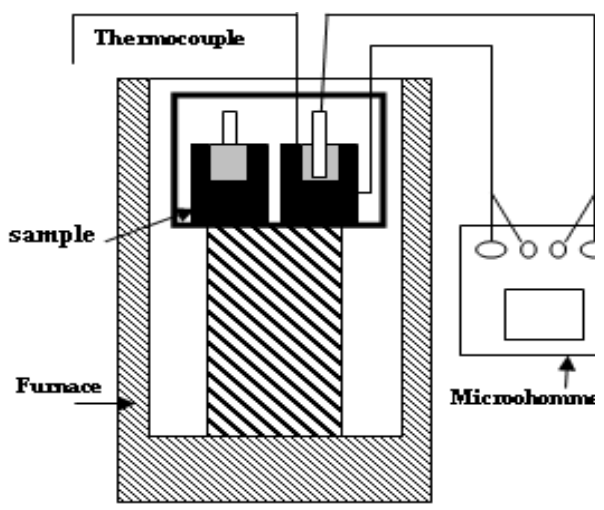

Figure 1 - Set-up for resistance measurement

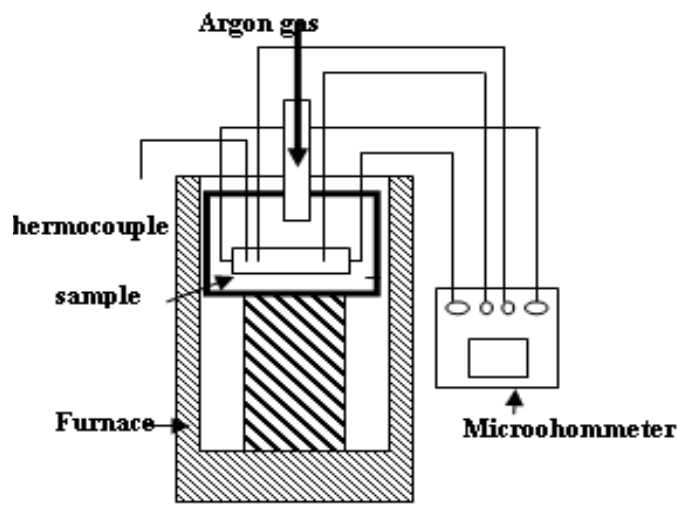

Figure 2- Set-up for electrical resistivity measurement

\section{5- Thermal expansion measurements}

The thermal expansion for the stub material (Steel 37) as well as the HPGI samples for $3 \mathrm{~mm}$ diameter $\mathrm{x} 10 \mathrm{~mm}$ length samples using a fully automatic dilatometer were tested and evaluated. 


\section{RESULTS AND DISCUSSION}

\section{1- Actual chemical composition for the existing HPGI}

30 blocks were selected from the rodding plant, putted in the cells then removed day by day during the anode life cycle and analyzed. The chemical composition for the as cast HPGI is shown in Table 2 and compared with the typical chemical composition of HPGI [14]. This table illustrates as general that the C, Si, and P for the HPGI are relatively high and of course detrimental to the electrical conductivity properties. The concentrations variation for various elements of HPGI during the anode life cycle is illustrated in Figure 3. Chemical analysis of collars withdrawn at different service times shows that the HPGI collars undergo continuous decarburization during cell operation. The carbon content in HPGI during anode life cycle was reduced significantly from 3.73 to $3.38 \%$. This is due to significant mass transfer occurred via diffusion between the HPGI and the steel stub. Follow up the change in the chemical composition of HPGI collars during anode life cycle shows that the carbon content in this alloy must be compensated when the recycled collars are used and remelted.

The other elements show some little variations in their concentrations. Sulphur content in HPGI during anode life cycle was increased from 0.04 to $0.06 \%$, where the HPGI pick-up sulphur from the surrounding anode carbon block. But this result gives rise to the assumption that sulphur does not only bind with HPGI by solid diffusion but more likely by reaction with a sulphur-containing gas phase, for example, COS [10]. C. Labrecque, et al. [6] confirmed that the phosphorus is present as a chemical compound in rodding, it will not diffuse as readily as carbon towards the steel stub and tends to form an alignment of phosphides parallel to steel stud-rodding interface; that reduces the conductivity of the rodding. So that, this work is based on reducing the percentage of phosphorus in the HPGI melt.

Table 2- Chemical composition for the typical and the as cast HPGI

\begin{tabular}{|l||c|c||c||c|c|}
\hline \multicolumn{1}{|c|}{ Element, \% } & C & Si & Mn & P & S \\
\hline Typical HPGI & $3.0-3.8$ & $2.5-3.5$ & $0.4-0.8$ & $1.4-1.6$ & $<0.05$ \\
\hline The as cast HPGI & 3.8 & 2.33 & 0.94 & 0.81 & 0.04 \\
\hline
\end{tabular}

\section{2- Collar temperatures, anodic voltage drop variation at the stub- collar - anode connection and anode current measurements}

The actual collar temperatures and the anode current dependence on the anode cycle service life under normal cell operating conditions are shown in Figure 4 obtained using the same method as in [14], while Figure 5 shows the anodic voltage drop variation with time at the stub-collar- anode connection.

The main observations from these figures may be discussed as:

- The collar temperature gradually increases over the anode life cycle and reaches to a maximum value (about $850^{\circ} \mathrm{C}$ ) in four weeks after the anode changing. 


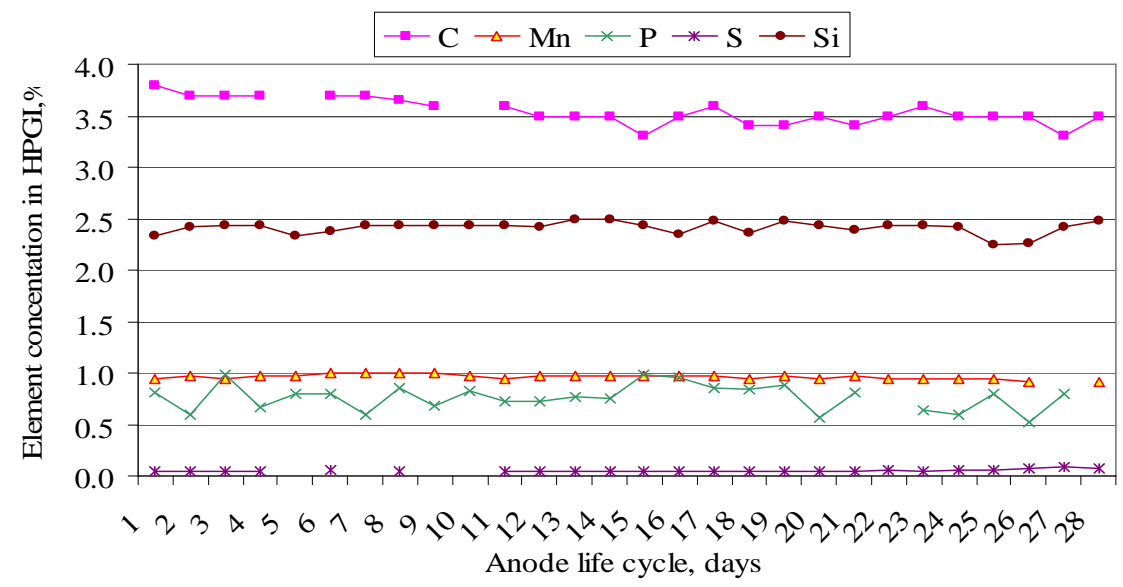

Figure 3- Variation in the chemical composition of HPGI collar during anode life cycle

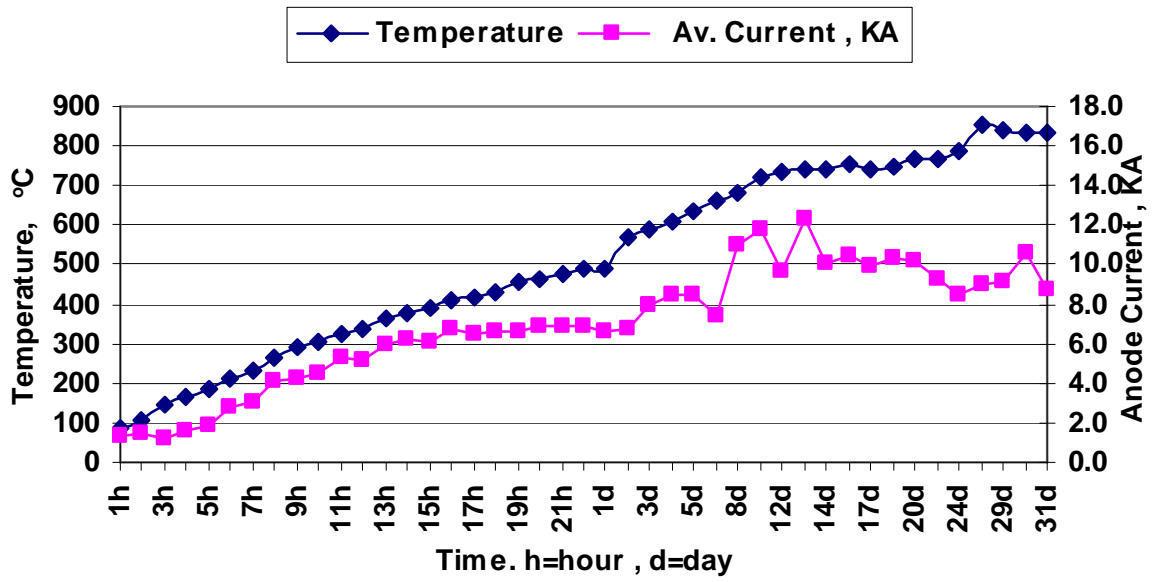

Figure 4- HPGI collar temperature and anode current during anode life cycle

- The slope of time-temperature decreases after about 10 days from the anode change when its temperature reaches the $720-750^{\circ} \mathrm{C}$ range. At this temperature two factors seem to have contradictory effects on the contact at the stub-collaranode connection the expansion due to graphite precipitation and the contraction due to the ferrite - austenite transformation at the eutectoid reaction of the HPGI. Although such contraction may be partly compensated by the same phenomena taking place in the steel stub, but the shrinkage of HPGI collar still plays a role in decreasing the contact at the connection zone.

- The anode current increases steadily with time, apparently due to precipitation of more graphite from the decomposition of pearlitic carbides and the resulting expansion of the collars will lead to more intimate contact at the stub-collar anode connection. Moreover, ferritization of the matrix with time and temperature will result in lower resistivity of the matrix and hence higher anode current. 


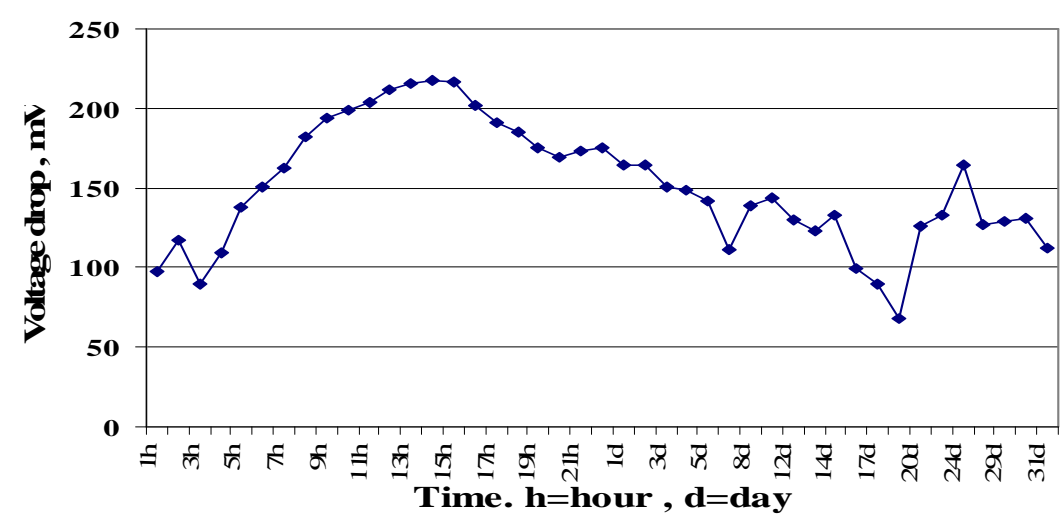

Figure 5- Anodic voltage drop measuring in an operating cell.

- The anodic voltage drop increase over the first 15 hours of operation (Figure 5) may be related to the increased amount of graphite in the HPGI which reduces the electrical conductivity of the collars up to $400^{\circ} \mathrm{C}$. Further heating of the collar leads to more expansion and better contact at the connection zone which will result in continuous decrease in the voltage drop. The anodic voltage drop again rises and shows two peaks after 10 and 21 days, the first peak at 730$750^{\circ} \mathrm{C}$ may be related to the $\alpha \rightarrow \gamma$ transformation contraction, whereas the second peak at $850^{\circ} \mathrm{C}$ may be due to the relief in contact pressure as a result of:

i) Creep of the steel stub which will lead to slight decrease in its diameter and/or

ii) Softening of the iron structure due to melting of the intercellular phosphide phase.

\subsection{Microstructure of HPGI Collars}

The microstructure of the HPGI collars during the anode life cycle was studied. The actual as-cast microstructure of such iron is shown in Figure 6-a consisting of interdendritic distribution of the phosphide ternary eutectic (iron phosphide cementite- austenite) typical of high phosphorus irons [14]. As the HPGI was poured between steel stub and graphitic anode; both are of high thermal conductivities, the HPGI was subjected to solidification under high chilling conditions which result in higher degrees of undercooling and the formation of such fine undercooled graphite. As iron phosphide eutectic solidifies at rather low temperatures $\left(850-900^{\circ} \mathrm{C}\right)$, it appears as intercellular formations in between the primary austenite dendrites, which would later transform to pearlitic dendrites at the eutectoid transformation temperature range.

It should be noticed that further heating results in significant changes in the microstructure of the HPGI collars. Figure 6-b shows that after 3-days from the anode change, its temperature reaches about $550^{\circ} \mathrm{C}$ (Figure 5) and the matrix undergoes considerable ferritization with the precipitation of some spheroidal graphite particles. This latter phenomenon was related to the increased S-pick up by the HPGI collars from the graphitic anodes [1]. At the end of the anode life cycle, i.e. after 30-days, ferrite dominates the collar structure and phosphide inclusions still exist in the structure with more or less rounded morphologies due to the remelting process they undergo over $850^{\circ} \mathrm{C}$ (Figure 6-c). 


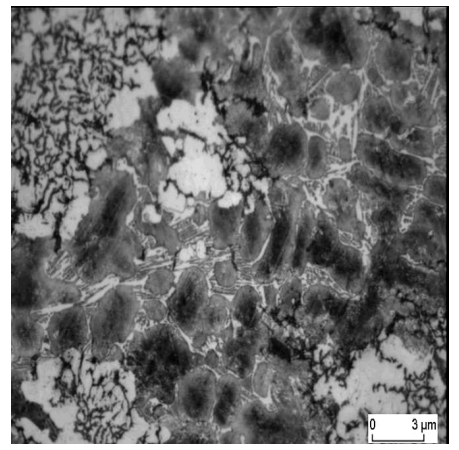

(a)

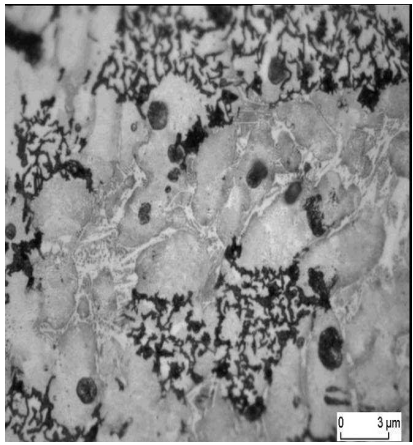

(b)

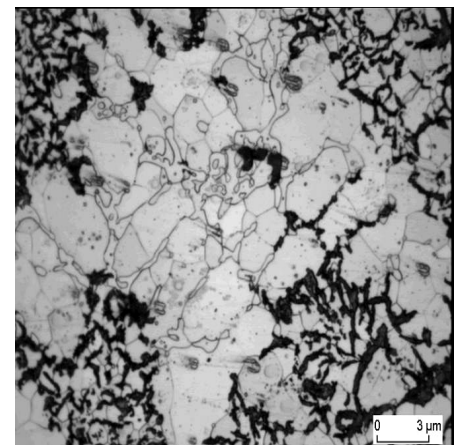

(c)

Figure 6-Microstructure of HPGI; (a) as-cast; (b) after 3-days operation, and (c) after 30 days operation.

\section{4- Electrical resistivity and resistance measurements}

The resistivity of all the investigated HPGI samples as well as the steel sample increases steadily with temperature as shown in Figure 7. As expected steel sample had the lowest electrical resistivity, the difference between steel and HPGI resistivity, however, little decreases with increasing temperature

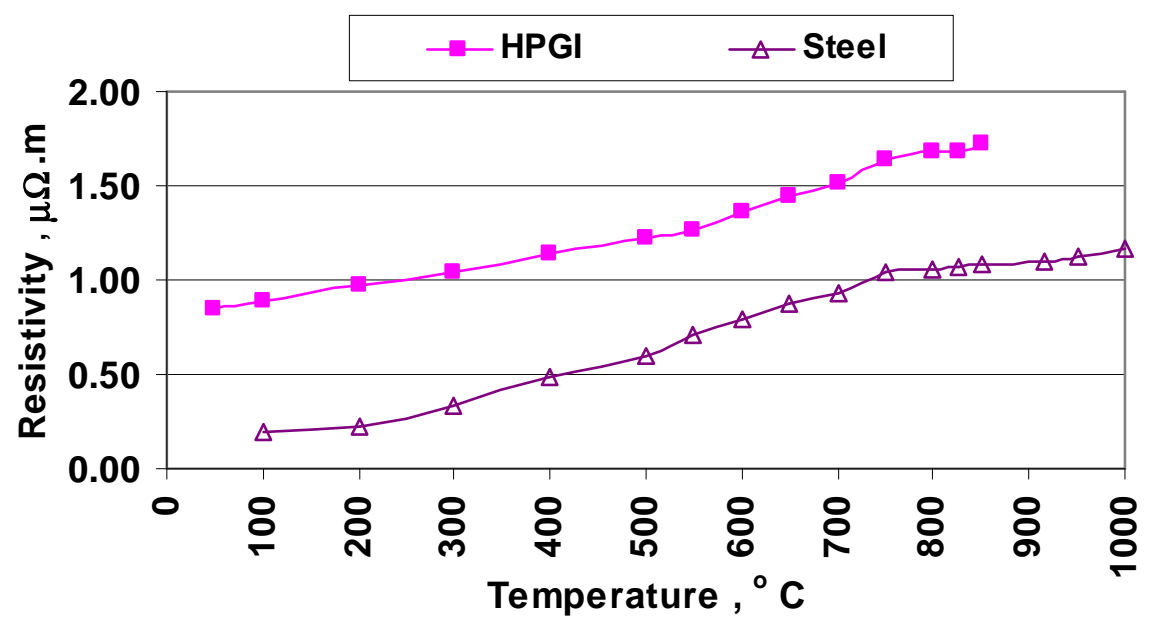

Figure 7-Electrical resistively of HPGI compared to steel.

Figure 8 illustrates the electrical resistance at the stub-collar-anode connection. At lower temperature of $500^{\circ} \mathrm{C}$, the resistance of connections seems to be slightly higher than those at the highest measured temperature of $850^{\circ} \mathrm{C}$. This indicates that other factors, rather than the electrical resistivity of the collar contribute to determining the resistance of the stub-collar-anode connection. These results showed the greatest importance to modify the current used HPGI or producing a new alloy with excellent electrical and mechanical properties. 


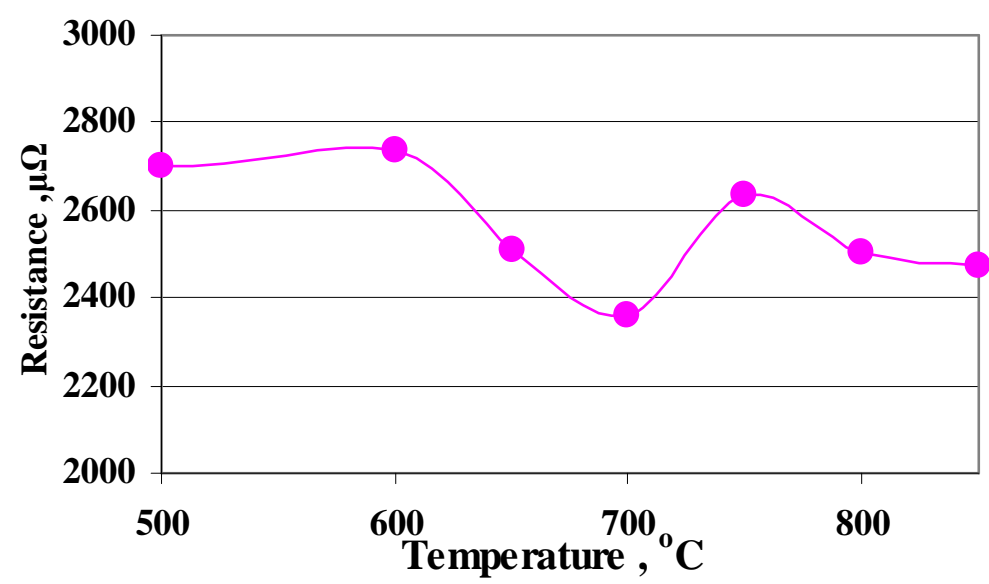

Figure 8- Connection resistance of HPGI collars

\subsection{Thermal expansion measurements}

The thermal expansion curves for the stub materials Steel37 $[10,15]$ as well as the HPGI samples are shown in Figure 9. Steel curve shows typical contraction and expansion on heating and cooling, respectively, associated with the eutectoid reaction and the formation of the more closed-packed austenitic structure on heating. It is interesting to notice that the HPGI shows considerable permanent expansion after the completion of the heating-cooling cycle. The heating expansion in microns of the HPGI and steel at both $849^{\circ} \mathrm{C}$ and $949^{\circ} \mathrm{C}$ temperatures is illustrated in Table 3 .

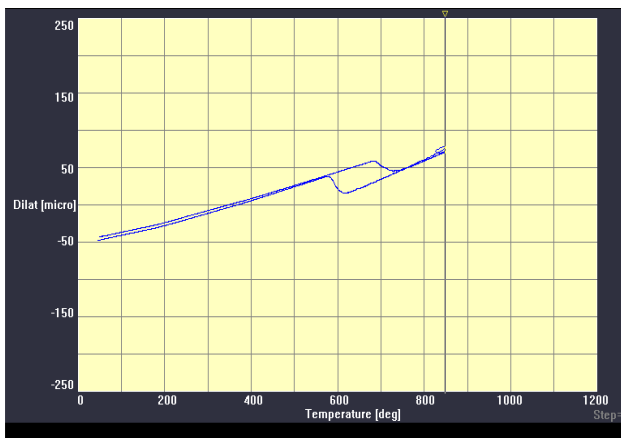

(a)

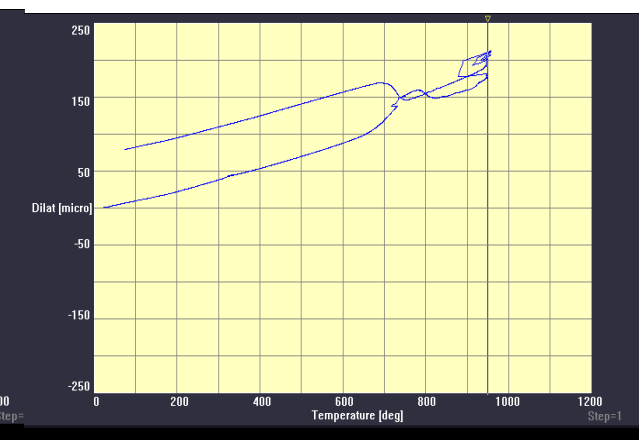

(b)

Figure 9- Thermal expansion curves of a) Steel, b) HPGI

Table 3. Heating expansion of steel and HPGI.

\begin{tabular}{|l|c|c|}
\hline Temperature, ${ }^{\circ} \mathrm{C}$ & Steel & HPGI \\
\hline 849 & 75.6 & 151.6 \\
\hline \hline 949 & - & 209.8 \\
\hline
\end{tabular}

The behavior of the HPGI, however, may be confusing. This alloy shows higher values of thermal expansion under the free unrestricted expansion conditions 
during dilatometric tests, most probably due to the melting of the intercellular phosphide phase formed around the eutectic cells in the iron microstructure. The expansion conditions in the gab between the steel stub and the carbon anode, however, seem to be different, where the expansion is more restricted by the confined volume in the gap. Expansion pressure may be partially or completely relieved due to the "cushioning" effect provided by the molten phosphide layer at the grain boundaries [10]. Under expansion pressure the grains may undergo relative sliding along the molten boundaries which will decrease the expansion forces leading to lower contact pressures and higher electrical resistance at the stub-collar-connection. This mechanism may explain the much less steep line of the resistance vs. temperature relationship of HPGI shown in Figure 8. Moreover, the formation of the molten phosphide intercellular layer at higher temperatures of $850^{\circ} \mathrm{C}$ may largely contribute to the increased electrical resistance at the connection shown in Figure 8.

\section{CONCLUSIONS}

- A continuous decarburization of HGPI collar during anode life cycle demonstrates that significant mass transfer occurred via diffusion between the HPGI and the steel stub, while other elements of the HPGI are still constant with some little variations in concentration.

- HPGI melt with reducing the phosphorus percentage must be taken into account to reduce the electrical resistivity of HPGI.

- Maximum collar temperature reached to $850^{\circ} \mathrm{C}$ after four weeks from the anode changing.

- Measurements show three peaks for increasing the anodic voltage drop during anode life cycle.

- There is still margin for improvement of the stub-anode voltage drop by improving the current used HPGI melt or producing new alloys with excellent properties or modifying the current stub design.

- After 10 days from the anode changing, a graphite precipitation and the contraction have affected on the contact at the stub-collar- anode connection.

- Significant changes in the microstructure of the HPGI collars were observed after 3 -days and 30 days from the anode changing.

- Two bench- scale experimental set-ups has been designed and used to simulate the operating conditions in the steel stub/ HPGI collar/ anode block connection and used to measure the electrical resistance and resistivity respectively

- Considerable permanent expansion for HPGI after the completion of the heating-cooling cycle.

\section{ACKNOWLEDGEMENT}

The Authors would like to express their appreciation to Eng. Sayed Abdel Wahab chairman and executive director of Egyptalum for his support during this work. The great thanks to the contributions of heads of the production sectors, carbon and refractories sectors, technical sectors and head of R \& D sector of Egyptalum for saving the best conditions to success this work. The authors would like to thank the 
teams of R \& D and laboratories managements for their continuous helping during this work.

\section{REFERENCES}

1. M. Barstow, et al., "Efficient cast iron microstructure for anode -collars in gray or ductile irons", Light Metals, pp. 619-623 (1997).

2. Specification of anode rodding plant, Egyptalum (2008).

3. A. Chakrabarti, "Casting technology \& cast alloys", Prentice Hall of India Private Limited, New Delhi (2005).

4. R. Elliot, "Cast iron technology", Butterworth, London (1988).

5. F. Habashi, "Handbook of extractive metallurgy", Wiley-VCH, London, vol 1, (1997).

6. C. Labrecque, et al., "A new technology for cathode rodding used in aluminum electrolytic cells", Light Metals, pp. 661-667 (2003).

7. A. Burkin, "Production of aluminium and alumina", John Wiley \& Sons: New York (1987).

8. R. Peterson, "Temperature and voltage measurements in Hall cell anodes", Light Metals, pp. 365-382 (1976).

9. D. Brooks and V. Bullough, "Factors in the design of reduction cell anodes", Light Metals, pp. 961- 977 (1984).

10. S. Wilkening and J. Côté, "Problem of the stub anode connection", Light Metals, pp. 865-873 (2007).

11. K. Grjotheim and H. Kvanda, "Introduction to aluminium electrolysis ", Aluminium-Verlag GmbH, Düsseldorf (1993).

12. K. Grjotheim and B.J.Welch, "Aluminium smelter technology", AluminiumVerlag GmbH, Dusseldorf (1980).

13. B. Wood, Aluminium 5, pp. 71-73 (2007).

14. A. Nofal, M. Waly, Sh. Mohamed and M. Agour, "New solutions for stub-anode connection at Egyptalum", pp. 1073-1078, Light Metals (2009).

15. N. Kandev and H. Fortin, "Electrical losses in the stub-anode connection: computer modeling and laboratory characterization", Light Metals, pp. 10611066 (2009). 


\section{إستخدام الحيد الرمادى عالى الفوسفور فى ريط الثوكة مع البلوك الانودى فى خلايا}

\section{إستخلاص الألومنيوم}

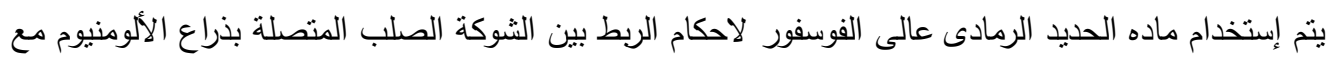

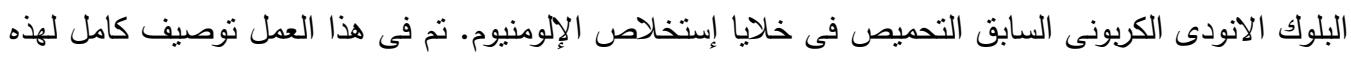
المادة. فقد تم دراسة كل من التغير فى التركيب الكيميائى لهذه الماده والجها المفقود على الأنود ودرجات الحرارة

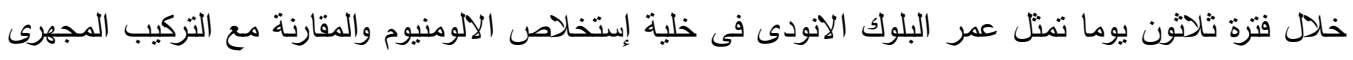

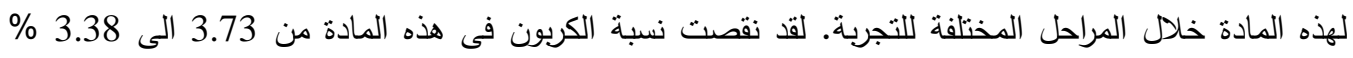

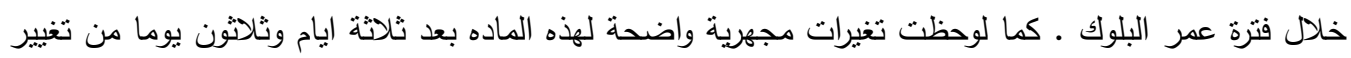

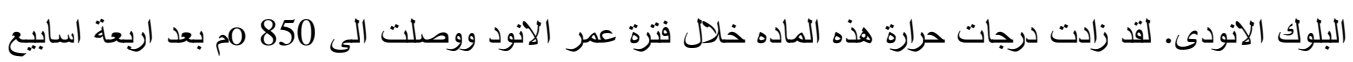

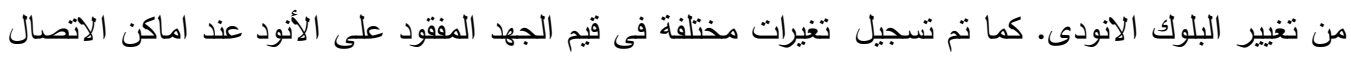

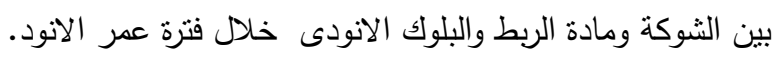

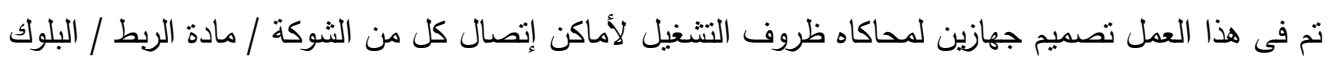

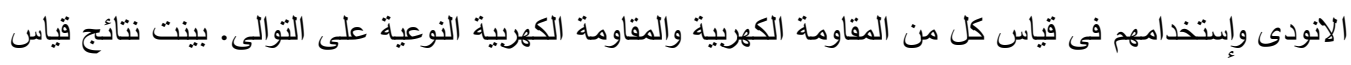

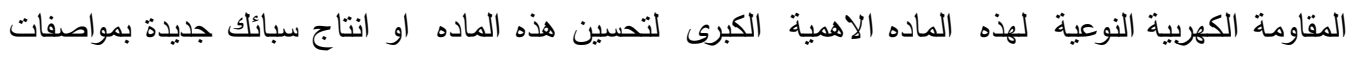

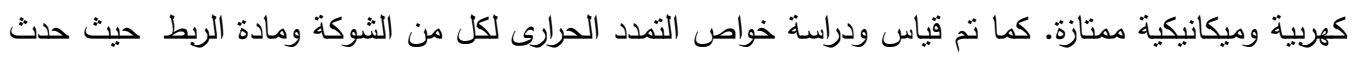
تمددا دائما لماده الربط بعد اكثمال دورة التسخين والتبريد. 